\title{
O PERIGO DA ESCRITA: MICHEL FOUCAULT, BELL HOOKS E UMA PESQUISA FEMINISTA - INSPIRAÇÕES QUE NOS AFETAM
}

\author{
Giovanna Marafon ${ }^{\mathrm{i}}$ \\ Yohanna Gomes de Souza Almeida ${ }^{\text {ii }}$ \\ Andrea Chiesorin Nunes ${ }^{\text {iii }}$ \\ Giordana Moreira Medeiros ${ }^{\text {iv }}$
}

\begin{abstract}
Resumo: Neste texto, problematizamos a relação afetiva com a escrita a partir da entrevista "O belo perigo", em que Michel Foucault conversou com Claude Bonnefoy. A entrevista inspirou nossa escrita de uma pesquisa em educação, relacionando-a também com bell hooks. Convocamos o campo da pesquisa feminista, voltado a investigar a produção de um coletivo de mulheres, na Baixada Fluminense, que é produzido com a música e com o audiovisual, visando a uma educação antissexista. Na fruição de episódios audiovisuais com bandas de roque, que entrevistam produtoras e musicistas, percebemos uma estética e conteúdos sobre feminismo, racismo, resistências e criações das mulheres na arte e na cultura, por meio dos quais buscamos dar corpo a uma "arte da escrita", continente da pesquisa em educação.
\end{abstract}

Palavras-chave: arte da escrita; Michel Foucault; bell hooks; pesquisa em educação; feminismo.

\section{EL PELIGRO DE LA ESCRITURA: MICHEL FOUCAULT, BELL HOOKS Y UNA INVESTIGACÍON FEMINISTA - INSPIRACIONES QUE NOS AFECTAN}

\begin{abstract}
Resumen: En este texto problematizamos la relación afectiva con la escritura a partir de la entrevista "el bello peligro", en él que Michel Foucault conversó con Claude Bonnefoy. La entrevista inspiró nuestra escritura de una investigación sobre la educación, relacionándola con bell hooks. Traemos un campo de investigación feminista, convocado para investigar la producción de un colectivo de mujeres en la Baixada Fluminense, un colectivo que con la música y audiovisual se dirige a una educación antisexista. En el deleite de episodios audiovisuales con bandas de rock, que entrevistan a productoras y musicistas, percibimos una estética y contenidos sobre feminismo, racismo, resistencias y creaciones de las mujeres en el arte y en la cultura, por medio de ellos buscamos darle un cuerpo a un "arte de la escritura" continente en la investigación en educación.
\end{abstract}

Palabras clave: arte de la escritura; Michel Foucault; bell hooks; investigación en educación; feminismo.

\section{Michel Foucault e bell hooks: inspirações que afetam}

Gostaria que essas conversas se situassem, se não em sua totalidade, ao menos em grande parte, à margem de seus livros, que elas nos permitissem descobrir o avesso deles, algo como sua trama secreta. O que me interessa em primeiro lugar é sua relação com a escrita (FOUCAULT, 2016, p. $33)$.

Compreender o avesso da escrita, algo como sua trama secreta, foi o mote da entrevista "O belo perigo" "o belo perigo", realizada por Claude Bonnefoy a Foucault e que resultou em novas escritas, para nosso deleite. Aquele encontro no profícuo ano de 1968, na França, abriu espaço para a narrativa da relação 
de Foucault com a escrita, que apenas recentemente foi traduzida para o português na forma do livro intitulado "O belo perigo - conversa com Claude Bonnefoy" (2016). Já no primeiro texto de tal coletânea, encontramos "Foucault e a arte da escrita", de Jean Marcel Carvalho. Percebemos que há em Foucault uma arte da escrita minuciosa, sedutora, com limites e potencialidades. Há também uma relação afetiva com a arte da escrita. A relação afetiva de Foucault com a escrita foi explorada naquela entrevista, sobretudo, e inspira-nos a reler esse importante autor cujas itinerâncias para a educação e, precisamente para a escrita, podem ser perscrutadas. Movemo-nos com as itinerâncias e com os deslocamentos, tanto físicos e geográficos quanto de sentidos, experimentados ao escrever.

Junto à leitura da arte da escrita de Foucault, trazemos também a arte da escrita de bell hooks autora, professora, crítica cultural, artista, teórica feminista negra estadunidense. Gloria Jean Watkins criou para si o pseudônimo bell hooks (propositalmente em minúsculas), relembrando e homenageando sua mãe Rosa Bell e sua avó Bell Blair. Foucault dizia que, para ele, escrever era "uma atividade extremamente suave, discreta. Tenho como que uma impressão de veludo quando escrevo" (Foucault, 2016, p. 43). Afirmava, ainda, que tinha da escrita uma ideia aveludada, que "é como que um familiar, no limite do afetivo e do perceptivo, que não para de assombrar meu projeto de escrever, de guiar minha escrita quando estou escrevendo, que me permite, a cada instante, escolher expressões que quero utilizar". (Foucault, 2016, p. 43). Mas, seus leitores reconheciam nele a "escrita seca e mordaz", e o próprio autor pensava que as pessoas poderiam ter razão, pois percebia em sua caneta uma "velha herança do bisturi" - feito para cortar - gesto herdado do pai médico. Por sua vez, bell hooks é reconhecida por uma escrita suave, apesar de cortante com o sexismov e com o racismovi ${ }^{\mathrm{v}}$, por ela enfrentados na vida e na arte da sua escrita. A autora não se cansou de afirmar que boa parte de sua obra em torno da teoria feminista busca destacar "os modos de o racismo e o machismo representarem sistemas interligados de dominação que se reafirmam e se sustentam mutuamente" (hooks, 2019, p. 133). bell hooks apresentou sua relação afetiva com a escrita em diversos livros e identificamos para esta discussão o livro traduzido para o português "Ensinando a transgredir: a educação como prática da liberdade" (2013), que nos tem sido fonte de inspiração e afetação.

Nessa obra, em que bell hooks se vale do que aprendeu com o estudo de Paulo Freire, em termos de uma educação para a liberdade e para a autonomia, ela nos conta sobre sua vida estudantil no sul rural dos Estados Unidos, em escolas segregadas para negros. Foi naquela experiência que bell hooks aprendeu a ter prazer com o que estudava e com suas professoras. Estudar como resistência e com a potência de uma educação antirracista. Conta-nos, depois, como foi árdua a trajetória nas escolas em que mais tarde havia integração racial, onde sofreu inúmeras práticas racistas, de educação para a dominação e para a obediência. Posteriormente, passou por uma formação superior e de pós-graduação também marcadas pelo racismo e se tornou professora universitária, a primeira em sua família, ensinando em cadeiras como "Estudos das Mulheres", "Estudos de Gênero" e "Literatura afro-americana", tendo como perspectiva uma educação para 
a transgressão, inclusive em relação ao feminismo branco vii . Com um capítulo intitulado "Paulo Freire", a autora cria o que chamou de um diálogo lúdico em que ela, Gloria Watkins, conversa com bell hooks, sua "voz de escritora": "quis falar sobre Paulo e sua obra deste jeito porque ele me proporciona uma intimidade - uma familiaridade - que não me parece possível alcançar na forma de ensaio" (hooks, 2013, p. 65). Assim, a entrevista foi o jeito encontrado por bell hooks para escrever a respeito do que aprendeu com Paulo Freire: "E aqui encontrei um modo de partilhar a doçura, a solidariedade sobre a qual falo" (hooks, 2013, p. 65).

Em vez das itinerâncias bem estabelecidas, maiúsculas, dos autores em tela, propomo-nos a escritas, diríamos, em minúsculas. Vamos em direção a Foucault e a bell hooks, pelo que ele e ela nos permitem encontrar como caminho que repercute em nossa escrita. Foucault porque, de seus muitos ditos e escritos, ouvimos o "estilo musical do autor", ao qual Carvalho (2016) fez menção, a partir do trabalho de Paul Veyne por ele citado. Com "estilo musical” e uma cadência das frases, como descreveu Bonnefoy na entrevista a Foucault, compreendemos o alcance deste autor, de sua "arte da escrita", espalhada por diversos meios e modos: livros, entrevistas, coletivas de imprensa, aulas, artigos, palestras em sindicatos, grupos de estudos nas prisões e até comícios. Foucault foi um autor que não se furtou de ampliar sua voz e na entrevista de 1968 revelou seu processo de escrita até ali. bell hooks porque, com seus escritos embebidos em vida vivida e análises para transpor o racismo, o sexismo e o classismo para transgredir e afirmar uma educação libertadora, ilumina matérias de escrita que habitam também em nós, mulheres vinculadas aos feminismos e aos fazeres acadêmicos por meio da arte e da cultura. bell hooks nos ensina, entre tantas lições, a "erguer a voz".

Nas inspirações para escritas acadêmicas, neste movimento, chegamos a Foucault para um mergulho no perigo da escrita, por meio de uma entrevista em que revela como constituiu seu vínculo com a "arte da escrita". Em outras palavras, como ele foi afetado pela escrita na entrevista em que reconhece que sempre teria tido para com a escrita "uma desconfiança quase moral" (FOUCAULT, 2016, p. 36). Ele, que teve alguma depreciação em relação à escrita na infância, no meio de racionalidade médica no qual vivia, cujos valores eram opostos aos da escrita. Anos depois, mesmo com o hábito de fazer análises literárias, redigir dissertações, passar por exames, Foucault assume que aquelas atividades: "não contribuíram muito para criar em mim o gosto pela escrita. Muito pelo contrário" (FOUCAULT, 2016, p. 38). Muito pelo contrário! Isso também é o que afirmam a maioria de estudantes das licenciaturas na formação de professoras(es). Desafio imenso nos ocupa para compreender como é a escrita para estudantes que chegam à universidade e fazem pesquisa na graduação e na pós-graduação. E mais, como discutir a escrita? E, a escrita da pesquisa pode contribuir com a pesquisa em Educação? Como tentativa-percurso, que enfrenta perigos, tecemos este texto.

$\mathrm{Na}$ entrevista, Foucault surpreende quando afirma: "para descobrir o prazer possível da escrita, foi preciso que eu estivesse no exterior" (FOUCAULT, 2016, p. 38). Ele se referia à experiência que teve 
vivendo na Suécia, onde teve de falar os idiomas sueco e inglês, impossibilitado de utilizar a própria língua e limitado em línguas que não conhecia tão bem, entendeu que poderia então habitar a língua que era a dele. “Ali onde não é mais possível falar, descobre-se o encanto secreto, difícil, um pouco perigoso de escrever" (FOUCAULT, 2016, p. 39). Em algum exterior da fala, ele parece ter encontrado espaço para escrever, com perigos, encantos secretos e dificuldades. Essa problematização nos afeta e nós, fazemos também essa interrogação-itinerância para ser perquirida com a escrita.

A inversão quanto à desvalorização primeira da escrita, para Foucault, adveio "por meio de um longo trabalho que, finalmente, atribuí a essa palavra tão profundamente desvalorizada, certo valor e lhe conferi certo modo de existência” (FOUCAULT, 2016, p. 41-42). Ainda de acordo com ele, suas interrogações residem no modo de aparição de funcionamento do discurso real, sobre aquilo que foi efetivamente dito, quer dizer, "trata-se de uma análise das coisas ditas na medida em que são coisas" (FOUCAULT, 2016, p. 43).

Dando continuidade ao movimento, encontramos bell hooks para disparar transgressões em nossas escritas acadêmicas, para criar gosto pela escrita, tal como aprendemos com ela nos textos escritos como entrevistas, nos quais bell hooks revela como se afetou pelas leituras, entre a criação e a imaginação. Nesse sentido, "somos afetadas" pelo que afetou a escrita de cada autor(a) e que a cada leitura nos afeta, assim como afeta a nossa própria experiência de escrita, na medida em que aceitamos participar ou sermos afetadas. Para tanto, tomando de empréstimo a proposição de Favret-Saada (2005) quanto a sua experiência de pesquisa de campo, em relação à qual afirmou dar "lugar à comunicação não verbal, não intencional e involuntária, ao surgimento e ao livre jogo de afetos desprovidos de representação" (p. 161), o que teve como efeito levá-la a explorar milhares de aspectos de uma "opacidade essencial do sujeito frente a si mesmo" (p. 161). Seguimos nos interrogando, portanto, a respeito do que afeta a escrita e como a pesquisa nos afeta.

Nossa escrita de pesquisa se dá nos encontros com Michel Foucault e com bell hooks para pensar e fazer a escrita em sintonia com a pesquisa acerca da produção cultural de mulheres, na dança e na música. Afetar-se está presente, pois lidamos com produções que nos afetam e sentimos que "outra educação é possível", como afirma Luana Tolentino (2018), autora brasileira que dialoga diretamente com o pensamento de bell hooks. Outra educação é possível com arte, com o perigo da escrita, com estilos musicais, dançando com os conceitos, com imaginação e criação.

Com Foucault, ao som de um "estilo musical", queremos colocar em análise o fazer de produtoras culturais feministas na Baixada Fluminense, material de pesquisa composto pelo que elas enunciam por meio do audiovisual na música, dando a conhecer seu processo de produção artística. Com a análise desse material, queremos também problematizar nossa vinculação afetiva à escrita da pesquisa. E com bell hooks, queremos escrever os des-locamentos de nosso fazer pesquisa com pensamento feminista e com práticas de 
liberdade, para uma educação antissexista e antirracista, que nos leve a recompor como escrevemos, descobrindo tramas secretas.

\section{Caminhos e descaminhos da escrita e de quem escreve}

quando começo a escrever ... não sei realmente aonde isso vai, nem em que vai dar, nem o que demonstrarei. Só descubro o que tenho para demonstrar no próprio movimento da escrita, como se escrever fosse precisamente diagnosticar aquilo que eu queria dizer no exato momento em que comecei a escrever (FOUCAULT, 2016, p.49).

Foucault nos convida ao movimento da escrita, sem saber ao certo para onde, um pouco sem saber o destino. Entrar em itinerância pelo movimento de escrever como quem fia uma tapeçaria. Escrever sobre a escrita se torna um desafio, se olharmos de onde esse escrever emerge e por quais caminhos o processo da escrita passa, pois há deslocamentos que pautam esses caminhos. Muitos são os deslocamentos que fazemos pela Baixada Fluminense (BF), onde acontece a atuação do coletivo feminista com o qual pesquisamos e solo sobre o qual nossa escrita ganha corpo. A BF tem uma rede de produção enorme, mesmo que não valorizada e pouco divulgada nos chamados centros, e inclusive tem uma grande produção que é protagonizada por mulheres. Pensando na Baixada Fluminense não há como não lembrar do trem, esse que é um dos principais transportes públicos da região. $\mathrm{O}$ trem tem um valor quase emocional para aqueles que dele dependem, o trem é a ponte móvel que possibilita os deslocamentos, mesmo aqueles que não são necessariamente desejados, mas muito precisos. Os trilhos passam por todas as produções, na dor e na alegria.

Essas produções estão presentes na arte, na cultura e na academia. A arte e a cultura, na Baixada, podem andar juntas e complementar-se uma à outra. A Baixada tem fortes vertentes da arte e da cultura, na contramão de uma fama de violência, morte e pobreza, é local de produções musicais, artísticas, culturais e científicas. A ciência aqui (d)escrita é composta pelas produções acadêmicas que são desenvolvidas na periferia do Rio de Janeiro, em instituições de ensino superior públicas, como: Universidade do Estado do Rio de Janeiro (UERJ) - Duque de Caxias , Universidade Federal Rural do Rio de Janeiro (UFRRJ) - Nova Iguaçu e Seropédica, Instituto Federal de Educação, Ciência e Tecnologia do Rio de Janeiro (IFRJ) - Duque de Caxias e Nilópolis, e Universidade Federal do Rio de Janeiro (UFRJ) - Duque de Caxias.

Com a força constitutiva dos coletivos e movimentos sociais nesse território, a arte se mistura à produção acadêmica e passa pelas dimensões sensíveis, afetivas e perceptivas, formando e criando modos subjetivos situados na BF. Parafraseando bell hooks (2013), para que possamos recuperar o direito à subjetividade: "é fundamental que insistamos em determinar como somos, sem depender de respostas colonizadoras para estabelecer nossa legitimidade" (p.68). A arte que subverte centralidades e marginalidades pode ser caminho formador, opondo-se à educação sem arte e, com isso, fazendo acontecer 
outra educação. Ainda, na afirmação de Angela Davis (2017, p.166): “A arte é especial por sua capacidade de influenciar tanto sentimentos como conhecimento". Para isso entendemos que se torna importante conhecer e fruir das produções de arte e cultura da e na BF. Com essa compreensão, portanto, acompanhamos o coletivo Roque Pense, coletivo feminista criado em 2011 por mulheres produtoras culturais. Pense é uma sigla, trazida de experiência anterior delas com o grafite e significa "por uma educação não-sexista". Temos, então: roque por uma educação não sexista. Entendemos a história e a atuação desse coletivo feminista realizando o acompanhamento de suas produções. Elas estão envolvidas com a organização de festivais de rock, criação de cineclubes, incentivo à participação de mulheres diretoras e atuantes no cinema, bem como viabilizam a realização de laboratórios de produção cultural feminista e oficinas voltadas à arte, à história e à cultura locais. E mais recentemente, nos últimos quatro anos, protagonizam um canal audiovisual centrado na música e na produção cultural feminista.

\section{Roque Pense e a produção feminista na Baixada Fluminense}

Roque Pense se tornou uma "rede de mulheres produtoras culturais engendrando novos modos de produção para um circuito de arte e cultura independente e antissexista"viii. Um dos laboratórios, em 2016, ensejou a criação de um cineclube feminista na Baixada, o Facção Feminista, com atuação em escolas. A Roque Pense possui um canal no Youtube ${ }^{\mathrm{ix}}$ no qual disponibiliza vídeos de festivais de roque organizados anteriormente (2012, 2013 e 2015) e a criação de três temporadas de produção do Estúdio RP! (2016, 20172018 e 2019). O Estúdio é composto por programas audiovisuais com música, poesia e arte urbana, nos quais as produtoras e as musicistas apresentam a proposta de trabalhar de um modo feminista e antirracista, de produzir arte, cultura e reivindicar direitos culturais e direitos das mulheres a vidas dignas na periferia.

Um meio para entrar no universo de constituição do Roque Pense é a entrevista concedida por Giordana Moreira à Rádio Kaxinawá, da Faculdade de Educação da Baixada Fluminense (FEBF - UERJ), para o programa Música Popular da Baixada Fluminense (MPBF) ${ }^{\mathrm{x}}$. Além de ouvirmos a entrevista repleta de histórias e locações artístico-musicais da BF e de bandas locais, como a banda Gente (banda do episódio \#2 da primeira temporada do Estúdio RP!, em 2016 ${ }^{\mathrm{xi}}$ ), também transcrevemos a entrevista para que ela seja um texto escrito com o qual, em parte, tecemos nossa escrita. Nessa entrevista, Giordana afirma que a trajetória de constituição da Roque Pense é:

um processo de fazer que acabou nos consolidando como uma rede onde a gente quer descobrir esse novo modo de fazer e o novo modo de fazer é nada mais nada menos que fazer sem sexismo. E não é só não ser sexista, a gente fazer um espaço em que não aconteça machismo, mas é propor para o mundo formas de enfrentar o sexismo, que não adianta você ter a sua instituição e falar "ah aqui ninguém é machista", você tem que se propor a lutar contra o machismo no mundo, por que é uma realidade. (livre transcrição, 2019) 
A partir do trecho acima, podemos entender que os caminhos que consolidaram a Roque Pense, nos nove anos de sua existência, como movimento independente e por uma cultura antissexista, passam por: afirmação política do desejo de mulheres estarem no meio cultural e musical; reivindicação de posição equânime em relação aos homens, que já dominavam esses espaços há muito tempo; anseio por ver mulheres tocando, compondo e se apresentando com as bandas nos festivais; por combater o sexismo nesses espaços e, sobretudo, por afirmar outros modos de fazer isso ser possível e em condições respeitosas para as mulheres. Com o acréscimo da percepção de que esse modo, por elas reivindicado, produz outras relações e formas de estar no mundo, de trabalhar coletivamente e de fazer música e audiovisual feminista desde a periferia. A denúncia do machismo revela a presença e a permanência deste na cultura quando a maioria das bandas, principalmente de roque, são compostas por homens; instrumentos como bateria e guitarra são frequentemente tocados por homens; espera-se que as mulheres sejam as companheiras heterossexuais deles, que sejam fãs, apoiadoras etc., mas não protagonistas, que são, do fazer musical. Além disso, não é habitual vermos homens oferecendo apoio a mulheres que tocam ou cantam e estão num palco fazendo o show. A situação inversa, no entanto, tornou-se corriqueira na nossa cultura.

A esse respeito, a apresentação da Banda Gente no episódio \#2 da primeira temporada do Estúdio Roque Pense mostra a força do enfrentamento ao sexismo e ao racismo. A banda Gente é uma banda da Baixada Fluminense, de "rock afro-brasileiro e música preta brasileira tão presente na periferia do Rio de Janeiro"xii, resistindo ao processo histórico de embranquecimento do roque. A banda é composta por uma mulher preta, Iolly Amancio (vocalista) e, na ocasião da gravação, mais quatro homens. Atualmente, em 2020, a banda continua com cinco integrantes, havendo também uma mulher branca. Em 2017, a Banda Gente lançou seu disco intitulado "somos todos silvas", sobrenome mais comum no Brasil.

Faremos a seguir uma descrição do episódio. Os segundos iniciais do episódio \#2 da primeira temporada contam com ilustrações de uma mulher em movimento, a silhueta se move com cores de batom sobre os lábios, unhas pintadas nas mãos que tocam guitarra, enquanto se ouve a vinheta musical do Roque Pense, apresentando por escrito o nome da Banda Gente no tamanho da tela. A filmagem faz o primeiro foco no rosto da vocalista e depois se movimenta sobre a mão de um participante da banda que toca uma guitarra metálica, em contraste com o fundo do estúdio. Há a passagem de volta para o rosto da vocalista, com o microfone suspenso a sua frente; uma luz avermelhada e outra azulada incidem sobre sua face, do fundo é projetada uma forte luz amarela que destaca o brinco prateado e ela diz: "somos a Banda Gente, uma banda da Baixada Fluminense!” (nome composto pela emoção da fala afirmativa). Em meio ao som dos instrumentos tocados, ainda suaves, com imagens parciais da banda, ela acrescenta:

Uma área muito rica de produção, a gente tem aqui o Roque Pense, a gente tem diversos coletivos que têm várias iniciativas espalhadas por toda região; então galera, vamos perder o medo porque 
existe muita coisa boa sim, que tá rolando sim, de muita qualidade, e que vocês estão perdendo por puro preconceito! (sorriso irônico) ${ }^{\text {xiii }}$.

Imediatamente depois dessa introdução, tem início a trilha musical em formato show sobre um palco. As músicas da Banda Gente versam sobre a vida na cidade partida pelas desigualdades. Entre as músicas que foram tocadas na gravação ao vivo, a primeira é: "Samba do trem" - sobre o cotidiano de quem trabalha e enfrenta o transporte público (trem) avariado, teme sanções e o desemprego, revoltando-se diante das opressões que se cruzam em sua vida enquanto moradora da periferia. A música transcorre com a interpretação firme da vocalista, com expressões e gestos corporais com as mãos (punhos cerrados em alguns momentos), com o olhar brilhante e incisivo, com variações de abertura da boca para tons sonoros mais agudos, movimento corporal no ritmo da música marcada por vitalidade, revolta, confronto com uma situação fora do controle pessoal, com imagens e focos alternados nos instrumentistas tocando guitarra, baixo e bateria, bem como no conjunto da banda:

Se o trem variou não sei/ Só sei que parou/ E se eu chego atrasado mais uma vez/ Eu sou descontado/ E é por isso que eu bato com força na porta do trem/ Se o trem variou não sei/ Só sei que parou/ E se eu chego atrasado mais uma vez/ Eu perco o trabalho/ E é por isso que eu bato com força na porta do trem/ Mais uma vez oprimido/ Mais uma vez humilhado/ Mais uma vez sem resposta/ Mais uma vez sem trabalho (Música "samba do trem”, Banda Gente).

Na sequência, entra uma nova vinheta com ilustrações de uma mulher falando no ouvido da outra, gesto acompanhado pela inscrição na tela da campanha da produção Roque Pense: \#amor sim, abuso não. A produtora Giordana Moreira aparece sentada em um banco elevado, no estilo entrevista, diante de um microfone, com a bateria da banda ao fundo no estúdio. Ela fala do propósito da campanha "amor sim, abuso não", fazendo referência à violência nas relações afetivas, amorosas, sexuais, de trabalho, nas universidades, em casa, na rua etc. E destaca que o tempo atual tem mais espaços para se falar de violências contra as mulheres, em suas palavras: “o Roque Pense quer falar disso, porque as jovens já estão falando disso". Imediatamente depois, entra na cena a fala de um jovem branca, escritora e cofundadora da Revista Capitolina (publicação online e independente para garotas adolescentes, com uma proposta acessível e ampla para romper com qualquer forma de opressão). Sofia Soter está num ambiente externo, aberto, com arte visual urbana pintada em muro atrás dela, com a imagem de Frida Kahlo ${ }^{\text {xiv }}$, dizeres sobre o machismo que não [me] cala, entre outras. Fala das agressões motivadas por gênero, que acontecem na vida das mulheres de forma contínua, tanto em ambientes de trabalho, quanto escolares, especialmente quando em relações hierárquicas em que os homens dominam.

A fala e a imagem de Giordana entram novamente na tela, como que estabelecendo um diálogo com a fala anterior de Sofia. Giordana diz que são violências que às vezes as pessoas nem sabiam que eram violências. $\mathrm{Na}$ alternância de falas e imagens, Sofia entra no vídeo novamente, dizendo que há uma percepção muito limitada do que é violência, que acontece somente quando chega a um certo patamar e se 
torna físico ou uma agressão verbal muito explícita, ou muito contínua ou muito visível. A argumentação segue com a imagem e o som de Mia Lopes, mulher negra, jornalista e integrante do Instituto de Mulheres Negras Flores de Dan, fundado em Salvador (BA), em 2004. Mia afirma que primeiro é preciso educar a mente para saber o que é violência, "tem mulher que está passando por situação de violência que nem ela percebe... então ela normalizou, ela relativizou tanto o que é violência que ela precisou tomar um tapa pra entender que ela tá sendo violentada". Ela segue a fala de fortalecer a percepção das mulheres e também a ação delas, gesticulando: “diga epa epa epa, baixe a sua mão! No meu corpo mando eu!” (sorriso afirmativo com brilho nos olhos).

De volta ao estúdio, o videoclipe segue com lâmpadas coloridas amarelas, ligeiramente desfocadas e a música "Por tua causa", da Banda Gente. Ouvimos o anseio por vida mais longa e vivível para um menino que pode ser morto no genocídio negro, menino que, como tantos, tem a mãe a sua espera - "menino levanta/ que não chegou a sua hora/ além do mais não quero ver/ ninguém sorrir por tua causa/ menino levanta/ que a sua mãe te espera em casa/ além do mais não quero ver/ ninguém chorar por tua causa". No fim da música, uma fala de Iolly sobre sexismo no meio musical, seguida pela fala de Giordana dizendo: “muito da história da mulher no rock'n'roll não foi contada e você pode ainda ver isso hoje pelos palcos, onde as bandas são compostas por homens e as meninas tão no público, né”. O episódio conta ainda com o testemunho de Ana Lúcia Rezende, do Coletivo Femenina, do Espírito Santo, que promove ações de protagonismo das mulheres na arte, na cultura e em suas vidas. Ela afirma que era aquela jovem que ia aos shows e queria "ser os caras da banda", então montou uma banda e quando foi composta exclusivamente por mulheres começou a experimentar as dificuldades, tanto de não tocar um show inteiro quanto de não serem chamadas para os shows. Fala que dialoga diretamente com a de Giordana na sequência, quando diz que é comum na produção cultural, na música e nas artes, "a teoria da incompetência da mulher sempre tá colocada e naturalizada nesses ambientes”. E para avivar a memória, diz Iolly:

mas não existe só o machismo como forma de opressão, existe também o racismo e nesse ponto a mulher negra sofre duas vezes porque ela sofre duas opressões juntas e indissociáveis. O roque, apesar de ter vindo da música negra, ele no meio desse caminho se desassociou do negro e meio que entrou num lugar onde o negro não poderia entrar e... a gente foi mudando isso, a gente foi vendo muitos homens negros se destacando no roque lá fora. Mas, mesmo se você for citar nomes estrangeiros você consegue ainda meio que contar no dedo. Mulheres negras então... (balançando a cabeça com ironia e gesto de vazio) são raras. Quando eu fui buscar referência eu me vi sozinha. Me vi sozinha no meio de um ambiente onde não havia representatividade pra mim. Então eu tive que criar né, me criar sozinha, criar referências sozinha e eu acho que as coisas vão começar a mudar, mas ainda pesa muito a questão do racismo e do machismo no meio do roque.

Na música "Cólera”, um menino cria e faz poesia com as palavras no interior de um lugar protegido em meio a situações precárias, de desamor, em meio a foguetes no morro. Na performatividade musical do episódio com a participação da Banda Gente, emergem a sonoridade e a visualidade do Estúdio Roque Pense, destacam-se os metais dos instrumentos, as curvas e os desenhos de fundo claro na roupa também 
escura da banda e, principalmente, a pintura facial africana no rosto da vocalista, destacando os olhos pretos, a boca que canta, o cabelo trançado e a pele negra. Uma estética de uma política cultural afirmativa que se enuncia e pode ser escrita: banda com uma mulher preta, da periferia, fazendo roque afro-brasileiro.

No âmbito da produção do audiovisual para a música, por continuidades sociais desiguais, comumente os homens estão em lugares de comando e organização, bem como nos demais espaços, tais como: filmagem, direção de fotografia, roteiro, edição, engenharia de som, iluminação etc. Fazer parte de outra realidade para as mulheres passa por enfrentar o sexismo, criar um modo feminista, no qual cabem olhares e práticas de desconstrução do racismo genderizado (Kilomba, 2019), que atinge de forma violenta as mulheres negras, tal como afirmou a vocalista Iolly. A desconstrução passa também por enfrentar lesbofobia, transfobia ${ }^{\mathrm{xv}}$ e competições que, para produzir vitoriosos, fabricaram hierarquizações que historicamente recaiam sobre as mulheres, inferiorizando-as. Até hoje, portanto, estar nesses espaços apresenta para as mulheres um clima de disputa com a situação.

Pensar a respeito do sexismo, que é uma forma de opressão contra a qual o Roque Pense age, levanos de volta à bell hooks entrevistada por Gloria Watkins. Naquela entrevista, bell hooks afirma que aprendeu com Paulo Freire a colocar em prática aquilo que se sabe, que se tem consciência, em um processo transformador. E quando questionada sobre como lidou com o sexismo na obra do autor, ela afirmou a dificuldade que enfrentou para fazer a crítica necessária, ao mesmo tempo, continuar "reconhecendo tudo o que é valioso e respeitado na obra” (hooks, 2013, p. 70). Para isso, ela recusou posturas omissas em relação à discriminação racial e sexual às mulheres, segundo bell hooks, é preciso acabar com o racismo e com todas as formas de dominação e agir contra a opressão, assim incorporamos seus ensinamentos em afecções e práticas.

Colocar em prática o que nos afeta é se fazer implicar na transformação dos meios de educar, recorrendo à educação como espaço fomentador de experiências em trocas criativas e fazer reconhecida a arte local e regional, com a produção de saberes localizados (HARAWAY, 1995). Outra educação é possível pela construção de acesso, como por meio da ampliação da produção de cada território. A pesquisa da qual participamos se complementa em modos distintos de nossos fazeres, entre estes convivemos com pessoas com deficiência e com elas aprendemos outros modos de existir. Dessa forma, nossa escrita também é uma descrição das cenas audiovisuais, como fizemos até aqui e a seguir faremos novamente. Com tal escrita descritiva, através de nossos olhares, percepções e afetações, compartilhamos partes do repertório do coletivo Roque Pense.

\section{No Estúdio RP: sons, luzes, vozes e escrita da pesquisa feminista}


Chegamos a participar das gravações do último episódio produzido para integrar a terceira temporada do Estúdio Roque Pense (2019). Em tela um projeto de audiovisual completamente produzido por mulheres: na equipe de produção e entre as musicistas convidadas. O episódio \#6 inicia com uma paisagem sonora e tem descrita a composição institucional que credencia o fomentador público, por meio da lei do Imposto sobre Serviço (ISS) - incentivo fiscal para investimento na cultura - como se apresenta nas logomarcas de patrocinadores que criaram um edital em nível nacional, da Oi Futuro. A realização tem os créditos do Roque Pense. Na sequência, está estampado na tela: Estúdio Roque Pense! $3^{\text {a }}$ temporada trazendo a visualidade da ação: “Apoie o Trampo das Minas, se inscreva, curta, compartilhe” ”vi , seguida do nome da dupla que protagoniza o episódio: Guitarrada das Manas.

Nessa apresentação surgem as artistas com seus instrumentos em cena, sob luz de show, aos poucos revelam-se as mãos das musicistas dedilhando as cordas, com seus rostos e toques nas guitarras em repertório regional, projetado em luz branca. No interior do videoclipe em circulação no canal do Roque Pense no Youtube encontramos a imagem das vozes compostas pela presença das entrevistadas, com depoimentos delas sobre a produção musical que desenvolvem. Uma luz verde ao fundo e na parede compõem o enquadramento da cena no estúdio onde se faz a gravação musical, situando o público que enveredou pela música em formato show, na ambiência do audiovisual.

Características das "manas": duas jovens mulheres da região norte do Brasil, com cabelos curtos e com cachos, em tons castanhos e coloridos com evidência no contorno da nuca, também usam argolas nas orelhas e uma delas tem um piercing no nariz. Noia - título descrito da música que elas tocam. Na sequência, reverberam swing na guitarrada, som regional característico do Pará. As compositoras movem seus corpos no ritmo e na ação que se compõem com o teclado e com a música eletrônica. Elas produzem guitarrada com equipamentos de música eletrônica, improvisam e fazem experimentação musical, mais um lugar para as mulheres na música.

Nesse momento, elas estão fazendo um show e, em suas performances, usam belos óculos escuros. As imagens são compostas pela revelação delicada de partes dos seus corpos, ora as mãos, ora a movimentação pendular pela batida da cabeça, como o encontro do olhar das duas no estúdio. O tempo todo, elas estão de frente, uma para a outra, criando uma atmosfera de aconchego em espaço de pesquisa e composição musical.

As luzes se alteram entre azul, âmbar, vermelho e verde, climatizando um estar ao vivo. O videoclipe revela a gravação. Na tela, aparecem em primeiro plano as imagens das "minas/ manas". Um foco/close, outro close/foco na beleza de mulheres paraenses. As imagens delas são intercaladas com o ambiente do estúdio de gravação, onde os bastidores se configuram em cenografia, como em um palco.

Como produção audiovisual, o foco segue nas expressões faciais delas. "Caras e bocas" marcam suas presenças fortes no debate da ausência das mulheres musicistas na produção do ritmo paraense 
guitarrada. Momento em que as imagens são reveladas, já que captadas, pela sutileza das mulheres que estão por trás das lentes, projetando ou na ilha de edição, selecionando as delicadezas do(s) encontro(s).

A sutileza em videoclipe marca a presença feminista na cena audiovisual, elas estão de frente uma para a outra, e o foco em uma delas afirma a expressão da indignação com o sexismo na cena da música brasileira, o que se percebe pela alteração da piscada de olhos, na virada do olhar que afirma indignação. Essa cena produz um corte na produção, um respiro cúmplice, e afirma o modo feminista de fazer. A imagem retorna ao primeiro plano e em evidência está o enquadramento visual em um dos lábios maquiado com suave brilho da cor da pele, a voz entoa posições políticas que revelam a crítica à dominação masculina na linguagem audiovisual. A produção deste trabalho é toda feita por um olhar sensível, de muitas mulheres cisgêneras $^{x v i i}$ e transgêneras ${ }^{x v i i i}$, ocupando funções de: produção executiva, direção, roteiro colaborativo, entrevista, curadoria, fotografia, som direto, técnica de som e mixagem, iluminação, montagem, identidade visual, redes sociais, assistente de produção, fotografia e consultoria.

Guamaense - título descrito da música seguinte, que é também o título do álbum ${ }^{\mathrm{xix}}$ lançado pela dupla. Som em batida eletrônica, tendo em evidência o som dos teclados por elas tocados. O cenário apresenta luzes variadas compondo a ritmação e o pendular das cabeças, olhares entrelaçados se mantêm em firme consistência. São dois teclados, um em frente ao outro, elas tocam e articulam os corpos em suaves movimentos contínuos do tronco reverberando na soltura das cabeças, embaladas pela própria produção musical, experimental, ali naquele instante ao vivo. Num contínuo enquadramento visual rítmico, surgem detalhes dos dedos nos instrumentos e dos botões do sintetizador de som.

Em plano central, o foco é o retorno da entrevista com as manas da guitarrada se expressando sem óculos, fora do show. As imagens seguem revelando os detalhes das expressões: risos, sorrisos partilhados e gestuais de braços e mãos em movimento. Ora elas encaram a câmera e constantemente se encantam, comunicam-se afetivamente em diálogo com quem lhes vê ou lhes escuta. Sentadas em luz degradê roxo/violeta, revelam o "trampo" da criação, da composição pela constante pesquisa em experimentação de ritmos e sequências em batidas que se repetem.

As cenas do videoclipe se fundem como em um documentário e se intercalam entre a levada musical como show e a entrevista, na qual compartilham a experiência marcada pelas opressões vividas por mulheres lésbicas no norte do país. Além das itinerâncias por elas encontradas através da arte brasileira regional e da sensibilidade antissexista. A luz verde em contraste com a cor de suas peles e de suas presenças traz firmeza e suavidade para quem assiste, ouve, dança e frui da musicalidade.

Estarmos em presença no episódio \#6 da terceira temporada do Estúdio Roque Pense com a dupla Guitarrada das Manas, Beá e Renata, foi especial e importante para nossa pesquisa, muito nos disse do por que a luta contra o sexismo tem que ser travada efetivamente, não como parte de um produto, ou em face da sua venda, mas porque elas são mulheres lésbicas na produção musical, inaugurando uma geração de 
mulheres na guitarrada paraense. Para elas, lutar é impreterível, quem são, quem elas defendem ser, abre espaço para uma posição em que elas se tornam parte da luta:

Renata - Eu participo de um projeto em Belém, que é um tributo a um mestre de Siriá do interior do Cametá. São nove homens e eu, é muito doido pensar que eu sou a única mulher numa banda de dez pessoas e o resto são todos homens e as vezes eu ainda me questiono sobre o meu lugar, meu papel nessa banda, por que eu sou mulher, eu não posso deixar de pensar ser mulher dentro disso.

Essa fala da Renata, na entrevista que aconteceu no Estúdio Roque Pense, faz relembrar bell hooks quando afirma em seu livro uma fala de Paulo Freire, que para ela havia se tornado um mantra: "Não podemos entrar na luta como objetos para nos tornarmos sujeitos mais tarde" (hooks, 2013, p.66). Tanto a Renata quanto a Beá se inserem nas lutas que as atravessam como sujeitas, possivelmente houve um processo que contribuiu para enxergar esse lugar de sujeitas. Nas palavras de bell hooks: “Oposição não é o bastante. No espaço deixado por aquele que resiste ainda há a necessidade do devir - da renovação de si mesmo" (hooks, 2019, p. 55). Por mais doloroso que possa ter sido, entendemos que são processos que passam por reconhecer e ter um pensamento crítico em relação aos acidentes que as mulheres atravessaram.

Com acidentes estamos nos referindo a Carla Akotirene (2018) que, a partir do pensamento da intelectual negra estadunidense Kimberlé Crenshaw, aborda as avenidas identitárias e os acidentes pelos quais as mulheres são acidentadas nessas avenidas da vida (acidentes caracterizados por racismo, sexismo, territorialidade, capacitismo, LGBTQI+fobia, xenofobia e tantos tipos de preconceitos, que estão inseridos nas estruturas de poder e opressão). E uma vez que reconhecemos que somos acidentadas em alguma(s) dessas avenidas, assumimos uma posição de luta situada, localizada frente às opressões, “inventando novas formas de existir e de resistir" (hooks, 2019, p. 56). Sobre isso, na entrevista, a dupla dialoga:

\footnotetext{
Beá- A gente já escutou bastante a galera falando: vocês têm que curtir a onda do feminismo, viajar nesta onda e se aproveitar disso.

Renata- E é tipo agora é a hora, mas depois vocês vão ser esquecidas e isso é muito triste, ter tido que lidar com isso.

Beá- Sendo que está na gente esse posicionamento político, olha pra gente em cima do palco, saca? Nós como pessoas, como mulheres, como lésbicas. E assumir isso, e debater isso e falar esse discurso, está na nossa vivência, está na nossa rua, está em tudo que a gente faz, na forma como a gente se comunica, na forma como a gente toca, então eu acho que a gente já conseguiu mostrar pras pessoas que é mais do que hype ${ }^{\mathrm{xx}}$ é vivência.
}

Com esse diálogo entre Beá e Renata, a despeito dos movimentos afirmativos que elas fazem, percebemos como persiste socialmente um discurso sexista que tenta capturar como "novidade" mulheres estarem visivelmente produzindo música e arte. Dizem para elas se aproveitarem da onda feminista, como se fosse uma moda, que supostamente vai passar. Elas então reafirmam que se trata de vivências, de 
produções na arte e na vida, mostrando como é preciso estarem sempre atentas para que os modos dominantes não solapem sua força de resistência e invenção.

Na casa da Beá - título descrito da música que segue, retomando o show, na qual ambas trazem suas guitarras aos corpos e com elas compõem junto aos teclados. Em meio à produção de alta qualidade musical, trazem também visualidade aos modos singulares de compor música independente e autoral, feita por mulheres. A direção de arte produz efeitos cromáticos, revelando uma estética contemporânea com requinte popular, construída sobre a simplicidade com os recursos disponíveis no estúdio Labsonica, da Oi Futuro. Promove um produto estético de ampla circulação para internacionalizar as produções musicais locais, dissolve barreiras de invisibilidade, produz ativismo em rede de mulheres produtoras culturais, afirmando um posicionamento político antissexista e, não necessariamente por meio das palavras, dizem coisas semelhantes (ainda que com diferenças), como nos disse Foucault: "não tenho de modo algum a impressão, nem mesmo a intenção, de fazer uma obra. Tenho o projeto de dizer coisas" (FOUCAULT, 2016, p.69). Novamente um Foucault em minúsculas, de uma arte também em minúsculas, sem a hierarquização das obras de arte com pretensões maiúsculas.

\section{As produções feministas em conversas e escritas}

\footnotetext{
Sei, de qualquer forma, que meus livros serão comprometidos pelo que digo, e eu também. É o belo perigo, o perigo divertido dessas conversas. Então deixemos aparecer esse parentesco, deixemos aparecer essa comunicação (FOUCAULT, 2016, p. 75).
}

A rede Roque Pense vem buscando situar as vivências das mulheres na música e inscrevê-las com autoria própria. Há uma gentileza da partilha em comum (e incomum) ao abrir espaços como o LabSonica para a Guitarra das Manas, para as cinco outras bandas e artistas que participaram da $3^{\mathrm{a}}$ temporada do Estúdio Roque Pense e, ainda, ao oferecer tempos restantes de gravação para músicas de bandas que estiveram com elas e que de outro modo, naquele momento, não teriam acesso a um estúdio daquela qualidade. O LabSonica se localiza no bairro do Flamengo, Zona Sul do Rio de Janeiro, espaço que diz sobre o acesso àquele estúdio, não era um local acessível a todas anteriormente, e elas são artistas que nada deixam a desejar e possuem um nível altíssimo de qualidade. Desde a periferia, elas abriram caminhos para ocupar o centro de produção musical na zona sul do Rio. Visivelmente, a curadoria da temporada teve cuidado e responsabilidade ao escolher cada uma das bandas e artistas e há uma revolução em curso no fazer musical tendo uma equipe integralmente composta por mulheres em um espaço como aquele.

As produções feministas desafiam a verticalidade das responsabilidades e promovem parcerias horizontais e renováveis, essas podem ser características do fazer que muitas mulheres tiveram de criar. E aqui precisamos estar atentas aos perigos de uma idealização ingênua dos feminismos e das feministas. A 
captura no atrofiamento é sedutora, então não podemos deixar de lutar contra as variadas opressões que podem se interseccionar mesmo em ambientes e espaços compostos exclusivamente, ou em sua maioria, por mulheres. Não basta ser mulher para agir de modo feminista antissexista, antirracista e sem LGBTfobia. Seguimos com as marcas de feminicídios, violências domésticas e institucionais, marcas dos muitos efeitos do sexismo em nossas vidas, reivindicando a erradicação das violências contra as mulheres, assim como do racismo estrutural.

Vivemos um momento político e de isolamento social no mundo, com a pandemia de coronavírus. Estamos fora das escolas, das universidades e dos espaços culturais, e não sabemos quando retornaremos nem como. A violência doméstica contra as mulheres, assim como contra crianças e adolescentes, aumentou. Em um breve levantamento feito por meio da ferramenta google acadêmico, encontramos vários artigos recentemente publicados no Brasil e no mundo. De acordo com pesquisadoras de universidades e centros de pesquisas fluminenses, segundo dados do Ligue 180, disponibilizados pelo que foi intitulado "Ministério da Mulher, da Família e dos Direitos Humanos", no período inicial do reconhecimento da pandemia no Brasil, em março de 2020, houve um aumento de cerca de $17 \%$ no número de ligações com denúncias de violência contra a mulher. Em acréscimo, afirmam as autoras:

No Rio de Janeiro, dados do plantão do Ministério Público Estadual revelam um aumento de 50\% nos casos de violência doméstica já no primeiro final de semana após os decretos estaduais que propuseram o distanciamento social, sendo a maior parte das denúncias envolvendo violência contra a mulher (Marques et al, 2020, p. 2).

É tempo de retomarmos as discussões, de sensibilizar subjetividades antirracistas e antissexistas em artes de educar e de escrever: "escrever, no fundo, é tentar fazer fluir, pelos canais misteriosos da pena e da escrita, toda a substância, não apenas da experiência, mas do corpo, nesses traços minúsculos que depositamos no papel” (FOUCAULT, 2016, p.66)

$\mathrm{Na}$ entrevista o belo perigo, Michel Foucault ofereceu pistas para observar o modo escrevente de seu corpo - entre nós, também escreventes, é possível compor a escrita com o pensar do autor como uma dança, além do que já foi dito e escrito referente ao "estilo musical" do filósofo. Pela dança, é possível sentir e reconhecer os movimentos da sua arte da escrita, seu texto de escrevente, conforme ele afirmou na entrevista:

Não sou, portanto, um escritor. Situo-me resolutamente do lado dos escreventes, daqueles cuja escrita é transitiva. Quero dizer, do lado daqueles cuja escrita destina-se a designar, mostrar, manifestar fora dela própria alguma coisa que, sem ela, teria permanecido, senão oculta, ao menos invisível. Talvez seja aí que exista, apesar de tudo, para mim, um encantamento da escrita (FOUCAULT, 2016, p. 68-69).

A escrita escrevente é transitiva, permite tornar visíveis algumas operações e opressões que teriam se ocultado, a exemplo dos sentidos, tornar visível e descritivo o que sentimos e o modo como um fazer 
nos afeta. Muitas vezes chega a ser surpreendente o que conseguimos escrever. Durante e depois da escrita, a mirada é de encantamento com o que se produz. O modo de escrita foucaultiana, além de musical, suscita incisão corpórea, como ocorre com os corpos de fazedoras/pesquisadoras em e pela dança. O texto do filósofo escrevente pode conter dureza diante do que expõe. Sua leitura cria possibilidades de conteúdo firme e cortante. Ele se expressa com ternura e circularidade e estas podem ser características específicas do dançar, da natureza e da produção de movimentos afetivos e perceptivos, próprios de corpos que se produzem na leveza e no pe(n)sar da vida em sociedade, na densidade do viver.

Foucault fez uma menção de valorização e reconhecimento do que havia aprendido com a leitura que fez de Friedrich Nietzsche. Para o francês, a filosofia nietzschiana tinha de lidar com o homem na medida em que este estava doente. Foucault então sugere que para o filósofo alemão, a escrita "era ao mesmo tempo o diagnóstico e a violência terapêutica das doenças da cultura" (FOUCAULT, 2016, p. 50). Em contrapartida, Foucault revelou um pouco mais adiante na entrevista que ele se admirava e se interrogava acerca das obras de indivíduos desclassificados pela sociedade, excluídos como doentes, e como poderiam funcionar de maneira absolutamente positiva em uma cultura. Nesse diapasão, ele cita Raymond Roussel e Antonin Artaud, cujas produções são muito positivas e o filósofo via aí a possibilidade de colocar em questão as dinâmicas sociais de inclusão-exclusão.

Em proposta de diálogo, pensamos com bell hooks na teorização da vida, da dor e do ser, como uma prática libertadora e, por vezes, uma prática que cura. Contudo, essa teorização do viver tem de ser feita de forma a alcançar a todos, por isso a Baixada Fluminense precisa de uma teoria que a alcance, que possa ser entendida e incorporada nas vivências das pessoas. A seguir, temos uma análise de bell hooks acerca da realidade dos Estados Unidos, com efeitos para pensar o Brasil da Baixada:

\begin{abstract}
Existem tantos contextos neste país em que a palavra escrita tem um significado visual mínimo, onde pessoas que não sabem ler nem escrever não encontram utilidade para nenhuma teoria publicada, seja ela lúcida ou opaca. Por isso, nenhuma teoria que não possa ser comunicada, numa conversa cotidiana pode ser usada para educar o público. (hooks, 2013, p.90).
\end{abstract}

Observamos esse movimento de uma teorização que comunica amplamente no Roque Pense, mulheres que tornam suas vivências parte da luta e se valem de palavras musicais e visuais. A idealizadora da Roque Pense e produtora Giordana Moreira contribuiu diretamente para tornar realidade um desejo de fazer música por mulheres, com mulheres e que interfere nos modos de produção musical, enfrentando a opressão sexista, e assim abriu as portas para tantas que desejavam fazer música, arte e cultura. Uma música que comunique, o que é importante ressaltar, músicas que falam de quem são as artistas que cantam, tocam ou produzem, de seus processos, dores e sofrimentos. Um fazer música e arte que expressa o cotidiano e o viver de mulheres negras, mulheres da BF, periféricas, mulheres lésbicas, mulheres trans. A Roque Pense 
se propõe a se colocar na luta contra o sexismo tendo as mulheres como protagonistas, incorporando suas vivências. A teoria é uma prática, como nos ensina bell hooks. Nesse sentido:

Se o testemunho pessoal, a experiência pessoal, é um terreno tão fértil para produção de uma teoria feminista libertadora, é porque geralmente constitui a base da nossa teorização. Enquanto trabalhamos para resolver as questões mais prementes da nossa vida cotidiana (nossa necessidade de alfabetização, o fim da violência contra mulheres e crianças, a saúde da mulher, seus direitos reprodutivos e a liberdade sexual, para citar algumas), nos engajamos num processo crítico de teorização que nos capacita e fortalece. (hooks, 2013, p.97).

São artistas que entendem que sua arte emergiu de quem são, do que vivem, de onde vieram e por quais caminhos passaram. Isso fortalece a sua luta por um feminismo que acolha todas as lutas, um feminismo que as liberte do sexismo, sem esquecer de lutar contra o racismo, por uma educação antissexista e antirracista. Elas são sujeitas de suas próprias lutas, baseiam-se nas suas experiências e se engajam na resistência por outros modos de vida. Aquilo que um dia foi instrumento só de dor se torna base para o processo de cura. Alcançam outras porque falam para e por muitas, mesmo quando só falam de si. A arte e a música podem ser teoria da vida e como disse bell hooks: "Cheguei à teoria desesperada, querendo compreender - aprender o que estava acontecendo ao redor e dentro de mim. Mais importante, queria fazer a dor ir embora. Vi na teoria, na época, um local de cura" (hooks, 2013, p.83). Esse trecho é a descrição de um fazer artístico, teorizar assim pode ser um jeito de interferir nos modos cristalizados da academia. Tomamos a escrita como caminho no qual a arte pode se misturar com a pesquisa em educação e com nossas vidas, com as vidas das mulheres.

\section{Considerações finais}

A levada coletiva da Roque Pense na produção cultural feminista na Baixada Fluminense faz difundir produções locais, material que nos permite produzir uma pesquisa com saberes localizados (HARAWAY, 1995). Esse encontro-espaço de produção coletiva fez surgir a necessidade de ampliar a escrita e tornar acessíveis os episódios para, como gesto de pesquisa, partilhar e articular com outras e outros pesquisadores, aproximando instituições de ensino superior e incentivando a disseminação das pesquisas no campo da Educação e da Produção Cultural.

Lendo bell hooks, a autora nos mostra como aprendeu, com Paulo Freire, a colocar em prática aquilo que se sabe e, de modo sensível, tentamos construir acessibilidades em produções acadêmicas, artes de educar, educar com a arte e contribuir para circular as potências regionais da periferia. Nas palavras de Angela Davis: "um dos mais estimulantes acontecimentos culturais progressistas é o movimento da música" (DAVIS, 2017, p. 178), que criou "pontes sonoras" entre diversos segmentos e movimentos, incluindo o movimento de mulheres. Na construção escrita, fizemos a descrição de imagens localizadas em contextos 
que revelam os episódios na leitura, caso não haja acesso à internet ou à apresentação visual. Outrossim para que exista acessibilidade em outros termos, por meio da escrita que imprime as afetações de quem frui das apresentações e cria uma maneira de narrá-las no texto.

Cada episódio tem sua licença poética, como um compartilhar encenado das sensações experimentadas, de quem vê e compartilha com cegos e videntes os modos poéticos das cenas artísticas. As escritas são compostas pelos corpos em cena, com a percepção da produção feminista no audiovisual, com narrativas e percursos que compõem a memória e a diferença no fazer coletivo da Roque Pense. Entendemos que houve muito trabalho desde a concepção e a formulação do projeto para concorrer ao edital nacional em 2018-19, bem como nos desdobramentos das etapas seguintes, que são: executar o projeto, compor a equipe, afinar as ideias coletivamente, a seleção curatorial, as direções de musical, de arte e de fotografia para definir enquadramentos na montagem - engrenagens que necessitaram "des-hierarquizar" relações de gênero e promover parcerias entre diferentes mulheres.

Acompanhar na pesquisa esse modo de produzir da Roque Pense foi oportunidade de ver de perto a funcionalidade de uma equipe feminista e engajada, muitas mulheres com forças e delicadezas, construindo com suas próprias referências, o que possibilita outras formas de produção. Provoca em nós também um olhar para uma outra (pesquisa em) educação, inspiradas por Luana Tolentino (2018), queremos imprimir no fazer científico uma forma gentil e coletiva de educar e de escrever a pesquisa em educação, acreditando que respeito e estima são fundamentais para sujeitas e sujeitos. No encontro das teorias com a teorização da Roque Pense, ao modo de bell hooks, podemos pensar uma forma de fazer isso acontecer na academia e uma maneira de nos situar e deslocar em meio às formas cristalizadas do produzir científico, também marcado por sexismos, racismos e tantas opressões, mais ou menos visíveis, como os assédios nas relações. Fazer marcado também, em grande medida, por uma escrita contida pelas prescrições da pesquisa. Aqui, em deslocamento, experimentamos os perigos de uma escrita continente da pesquisa em educação.

Pesquisar com a Roque Pense e suas formas de fazer feminismo nos permite desviar do discurso neutro e de uma escrita sem rosto. Curiosamente, contrariando algo que Foucault algumas vezes fez menção de ter desejado realizar - apagar a si mesmo, não ter rosto. Talvez por isso, neste momento, encontrar a entrevista "o belo perigo" tenha criado uma superfície de contato nova com o pensamento do autor, diálogos antes não imaginados e um encantamento de descobrir ser possível escrever com as referências de um autor que se desloca. Nas palavras dele na entrevista:

Estou fazendo com você uma espécie de experiência. Estou tentando declinar pela primeira vez, em primeira pessoa, esse discurso neutro, objetivo, em que nunca deixei de querer me apagar quando escrevia meus livros (FOUCAULT, 2016, p. 74-75)

Pegar nas referências pontuais de Michel Foucault e bell hooks que selecionamos para fazer a tapeçaria desta escrita foi um exercício e, também para nós, uma espécie de experiência (diferente) com o 
texto. Uma "arte da escrita". A maneira como nosso ímpeto de escrever foi se desalinhando, entre movimentos nada lineares, inclusive perigosos, possibilitou-nos falar de nós, um produzir pessoal que passa pelo político, importante para muitas. Com isso, fomos levadas a outros lugares, sendo nós não as mesmas por meio de escritos, itinerâncias e produções que dizem respeito também a quem somos, tornamo-nos, e o que vivemos - desejamos viver.

\section{Referências}

AKOTIRENE, Carla. O que é interseccionalidade? (Coleção Feminismos Plurais - Coord. Djamila Ribeiro). Belo Horizonte: Letramento/ Justificando, 2018.

CARVALHO, Jean M. Foucault e a arte da escrita. In: FOUCAULT, M. O belo perigo. Tradução Fernando Scheibe. Belo Horizonte: Autêntica, p. 7-11, 2016.

DAVIS, Angela. Mulheres, cultura e política. Tradução Heci Candiani. São Paulo: Boitempo, 2017.

FAVRET-SAADA, Jeanne. "Ser afetado". Tradução Paula Siqueira. Cadernos de campo, São Paulo, n. 13, p. 155-161, 2005.

FOUCAULT, Michel. Conversa entre Michel Foucault e Claude Bonnefoy, 1968. In: O belo perigo. (Tradução Fernando Scheibe). Belo Horizonte: Autêntica, 2016, p. 29-77.

HARAWAY, Donna. Saberes localizados: a questão da ciência para o feminismo e o privilégio da perspectiva parcial. Cadernos Pagu, Campinas, n. 5, p. 7-41,1995.

hooks, bell. Ensinando a transgredir: a educação como prática da liberdade. (Tradução Marcelo Cipolla). São Paulo: Martins Fontes, 2013.

hooks, bell. Mulheres negras: moldando a teoria feminista. Revista Brasileira de Ciência Política, n. 16, Brasília, p. 193-210, 2015.

hooks, bell. Anseios: raça, gênero e políticas culturais. (Tradução Jamille Pinheiro). São Paulo: Elefante, 2019.

KILOMBA, Grada. Memórias da plantação: episódios de racismo cotidiano. Tradução Jess Oliveira. Rio de Janeiro: Cobogó, 2019.

MARQUES, Emanuele. S. et al. A violência contra mulheres, crianças e adolescentes em tempos de pandemia pela COVID-19: panorama, motivações e formas de enfrentamento. Cadernos de saúde pública, Rio de Janeiro, v. 36, n. 4, p. 1-6, 2020.

MUNANGA, Kabengele. Por que o racismo e suas práticas e qual é a responsabilidade social que se espera dos profissionais que lidam com as questões da sociedade? Revista Brasileira de Psicologia, 02 (núm. esp.), Salvador, p. 7-15, 2015.

OLIVEIRA, Fabio e RODRIGUES, Liliana. Por uma educação TRANSgressora e TRANSfeminista: possíveis enfrentamentos à produção das ausências através da disciplinarização e subjetivação. Aprender Cadernos de Filosofia e Psicologia da Educação, Vitória da Conquista, ano XII, n. 20, p. 83-102, 2019.

TOLENTINO, Luana. Outra educação é possível: feminismo, antirracismo e inclusão em sala de aula. Belo Horizonte: Mazza Edições, 2018. 
Recebido em: 30/04/2020.

Aceito em: 06/08/2020.

\title{
Notas
}

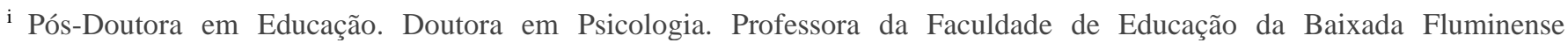
(FEBF/UERJ), do Programa de Pós-Graduação em Políticas Públicas e Formação Humana (PPFH/UERJ). Atualmente é vicecoordenadora do Programa Movimentos Sociais, Diferenças e Educação (PROMOVIDE - http://www.promovide.febf.uerj.br). Coordenadora da GIRA - Grupo de pesquisa em feminismos, relações raciais, deficiência e outras dissidências. E-mail: giovannamarafon@gmail.com Rio de Janeiro - ORCID: https://orcid.org/0000-0003-3423-4676

ii Estudante de Pedagogia FEBF. Bolsista de Iniciação Científica UERJ. E-mail: yohannagsa@gmail.com Rio de Janeiro. ORCID: https://orcid.org/0000-0002-7551-233X

\begin{abstract}
iii Mestranda em Políticas Públicas e Formação Humana pela UERJ. Bolsista CAPES (2019-2020). Graduada em Psicologia com licenciatura e bacharelado pela Universidade Gama Filho (UGF). Especializada em Políticas Públicas e Cultura por Direitos (UFRJ) e em Acessibilidade Cultural (UFRJ). Pesquisadora integrante da GIRA - Grupo de pesquisa em feminismos, relações raciais, deficiência e outras dissidências. E-mail: andreachiesorin@gmail.com Rio de Janeiro. ORCID: https://orcid.org/00000003-2514-3561
\end{abstract}

iv Produtora Cultural. Fundadora da Roque Pense. Estudante do Bacharelado em Produção Cultural - IFRJ Nilópolis. E-mail: giordanaxz@gmail.com Rio de Janeiro. ORCID: https://orcid.org/0000-0003-4543-0832

${ }^{\vee}$ No capitalismo, o patriarcado é estruturado de forma que o sexismo restrinja o comportamento das mulheres em algumas esferas, mesmo que, em outras, haja liberdade em relação a limitações. A ausência de restrições extremas leva muitas mulheres a ignorar as áreas em que são exploradas ou discriminadas e pode até levá-las a imaginar que as mulheres não são oprimidas" (hooks, 2015, p. 197).

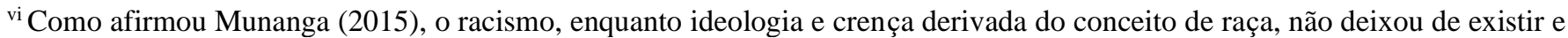
de fazer vítimas nas sociedades humanas do século XXI. E, com bell hooks (2015, p. 195-196): “apenas se analisando o racismo e sua função na sociedade capitalista é que pode surgir uma compreensão profunda das relações de classe. A luta de classes está indissoluvelmente ligada à luta para acabar com o racismo".

vii bell hooks problematizou os limites do feminismo (de mulheres brancas e de classe média), que excluía de suas considerações as posições e experiências de mulheres negras (hooks, 2015).

viii Sítio eletrônico da Roque Pense: www.roquepense.com.br

ix Trata-se do Canal Roque Pense no Youtube: https://www.youtube.com/user/roquepense

x Entrevista de rádio disponível em: https://open.spotify.com/episode/6LAao82bBfBdpa6vwHQYg8?si=v3WKyq6ESau7NvgIZ366Ig

${ }^{x i}$ Episódio audiovisual disponível em: https://www.youtube.com/watch?v=4WaZHrtq1-g

xii Sítio eletrônico da Banda Gente: https://www.bandagente.com.br

xiii https://www.youtube.com/watch?v=4WaZHrtq1-g

${ }^{\text {xiv }}$ Frida Kahlo (1910-1954) asteca, artista mexicana com uma deficiência física, em sua obra trata de corpos acidentados, dores, amores, luta política, interesse pelo inconsciente. Participou do primeiro manifesto surrealista, narrando amor, sofrimento, paixão, curiosidades, sensibilidade a partir da vivência de seu mundo, transformando-o em arte. Também foi discriminada pelo sexismo de sua época, que impôs restrições de visibilidade a sua produção, motivo pelo qual, entre outros, tornou-se ícone de reivindicações feministas. 
${ }^{x v}$ Entendemos com Oliveira e Rodrigues (2018) que a transfobia pode se apresentar em manifestações de "violência física, discurso de ódio, insultos (violência psicológica), exclusão e rejeição" (p.86). Concordamos com os autores que também os discursos estereotipados sobre gênero podem configurar transfobia.

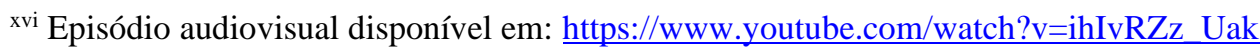

xvii $\mathrm{O}$ termo cisgênero foi cunhado para explicitar a norma que opera nos corpos e que é efeito de práticas sociais de gênero. Assim, pessoas cisgêneras são aquelas que se identificam no interior do padrão binário que designa desde bebês a identidade de meninos ou meninas de acordo com a leitura biomédica das genitálias.

xviii Transgêneras são as pessoas cujas identidades não são conformes às normas de gênero binárias, pois não se identificam com a designação que lhe foi atribuída ao nascer. Podem se identificar como transexuais, travestis e transgêneros.

xix Guamaense faz referência a quem nasceu ou mora no bairro Guamá, o mais populoso de Belém e onde se localiza a Universidade Federal do Pará.

${ }^{x x} \mathrm{Na}$ fala da entrevistada, "hype" pode ser ouvido como abreviação coloquial da palavra inglesa "hyperbole", que diz respeito a exagero, a algo que é enfatizado, também relacionado ao que está na moda, que é lido como atual. 